\title{
BMJ Open Relationship between maternal hypoglycaemia and small-for- gestational-age infants according to maternal weight status: a retrospective cohort study in two hospitals
}

\author{
Satoshi Shinohara, ${ }^{1}$ Yuzo Uchida, ${ }^{1}$ Mitsuo Hirai, ${ }^{2}$ Shuji Hirata, ${ }^{3}$ Kohta Suzuki ${ }^{4}$
}

To cite: Shinohara S, Uchida Y, Hirai M, et al. Relationship between maternal hypoglycaemia and small-for-gestational-age infants according to maternal weight status: a retrospective cohort study in two hospitals. BMJ Open 2016;6:e013749. doi:10.1136/bmjopen-2016013749

- Prepublication history for this paper is available online. To view these files please visit the journal online (http://dx.doi.org/10.1136/ bmjopen-2016-013749).

Received 5 August 2016 Revised 23 September 2016 Accepted 8 November 2016

CrossMark

For numbered affiliations see end of article.

Correspondence to Dr Kohta Suzuki; kohtas@aichi-med-u.ac.jp

\section{ABSTRACT}

Objective: The relationship between pre-pregnancy body mass index (BMI) and low glucose challenge test (GCT) results by maternal weight status has not been examined. This study aimed to clarify the relationship between a low GCT result and small for gestational age (SGA) by maternal weight status.

Design: A retrospective cohort study in 2 hospitals.

Setting: This study evaluated the obstetric records of women who delivered in a general community hospital and a tertiary perinatal care centre.

Participants: The number of women who delivered in both hospitals between January 2012 and December 2013 and underwent GCT between 24 and 28 weeks of gestation was 2140. Participants with gestational diabetes mellitus or diabetes during pregnancy, and GCT results of $\geq 140 \mathrm{mg} / \mathrm{dL}$ were excluded. Finally, 1860 women were included in the study.

Primary and secondary outcome measures: The participants were divided into low-GCT ( $\leq 90 \mathrm{mg} / \mathrm{dL}$ ) and non-low-GCT groups (91-139 mg/dL). The $\chi^{2}$ tests and multivariate logistic regression analyses were conducted to investigate the association between low GCT results and SGA by maternal weight status.

Results: The incidence of SGA was 11.4\% (212/ $1860)$, and $17.7 \%(330 / 1860)$ of the women showed low GCT results. The patients were divided into 3 groups according to their BMI (underweight, normal weight and obese). When the patients were analysed separately by their weight status after controlling for maternal age, pre-pregnancy maternal weight, maternal weight gain during pregnancy, pregnancy-induced hypertension, thyroid disease and difference in hospital, low GCT results were significantly associated with SGA (OR 2.10; 95\% Cl 1.14 to 3.89; $p=0.02$ ) in the underweight group.

Conclusions: Low GCT result was associated with SGA at birth among underweight women. Examination of maternal glucose tolerance and fetal growth is necessary in future investigations.

\section{Strengths and limitations of this study}

- To the best of our knowledge, this study is the first to clarify the relationship between low glucose challenge test (GCT) result and small for gestational age (SGA) by maternal weight status.

- We collected data from two hospitals, and the generalisability of the results may be relatively high.

- Conducting the analyses by each prenatal weight status was possible because the number of participants was relatively large.

- Data regarding history of childbirth, intake of alcohol and caffeine, antiphospholipid syndrome, maternal smoking status, kidney disease and inflammatory bowel disease were not considered in this study, although these are potential contributors for SGA.

- We hypothesised that low GCT results may have occurred as a result of high insulin sensitivity that has continued from early pregnancy, but we did not investigate the relationship between maternal weight gain and insulin sensitivity.

\section{INTRODUCTION}

Small for gestational age (SGA) is associated with increased perinatal mortality and morbidity $^{1}$ as well as future risk of developing obesity, cardiovascular disease and type 2 diabetes. ${ }^{2}$ Several studies suggested that prenatal identification of SGA is an effective preventive measure to reduce the risk of adverse perinatal outcomes and stillbirth, with appropriate close monitoring and timing of birth. $^{3-4}$ However, most SGA babies remain undetected via ultrasound until birth. ${ }^{5}$ Therefore, identifying the causes of SGA and defining strategies to improve early detection of SGA are important. SGA is attributed to many factors, such as aneuploidy, placental insufficiency, infection and connective tissue disease. $^{2} 6$ Moreover, several studies suggested 
that birth weight is related to insulin resistance in normal and gestational diabetic pregnancies. ${ }^{2}{ }^{7}$ For instance, Caruso $e t a \ell^{\S}$ reported that women with unexplained fetal growth restriction (FGR) have higher insulin sensitivity. The Japan Society of Obstetrics and Gynecology recommended the $50 \mathrm{~g}$ glucose challenge test (GCT) as a screening method for gestational diabetes mellitus (GDM) ${ }^{6}$ Women with abnormal GCT results (serum glucose levels of $>140 \mathrm{mg} / \mathrm{dL}$ ) subsequently undergo a $75 \mathrm{~g}$ oral glucose tolerance test for a definitive diagnosis. We have recently reported that a significant association exists between low GCT results and SGA infants. ${ }^{9}$ We hypothesise that high maternal insulin sensitivity is responsible for SGA infants. ${ }^{9}$ Similarly, an association between low GCT results and SGA infants has been reported. Insulin sensitivity is typically higher in underweight people than in overweight and normal weight people. ${ }^{10-11}$ Moreover, Catalano et al $\bar{l}^{7}$ stated that the development of insulin resistance in late gestation is a normal process in all human pregnancies and the development of maternal insulin resistance is associated with accretion of maternal adipose tissue in early pregnancy. In other words, although abnormal GCT results are not observed in the second trimester of pregnancy, differences in insulin sensitivity may exist at a later period of the pregnancy due to the weight status of the women before pregnancy.

To the best of our knowledge, no study until now has used both pre-pregnancy body mass index (BMI) and GCT results to develop more effective identification of fetuses at risk of SGA. In our previous study, we examined the association between low GCT results and SGA infants, but the association by maternal weight status was difficult to assess because of the small sample size.

In this retrospective multicentre cohort study, we used a relatively large sample and sufficient information regarding potential confounding factors for SGA (compared with the previous studies) ${ }^{12-15}$ of obstetric records to clarify the relationship between low GCT results and SGA by maternal weight status.

\section{METHODS}

\section{Participants}

We collected the obstetric records of women who delivered in a general community hospital and a tertiary perinatal care centre in Japan between January 2012 and December 2013. This retrospective cohort study included all women who underwent GCT between 24 and 28 weeks of gestation. Similar to our recent research, we excluded cases of GDM or diabetes in pregnancy because they have an increased risk of macrosomia or large-for-gestational age infants. We also excluded women with GCT results of $\geq 140 \mathrm{mg} / \mathrm{dL}$ because their glucose metabolism may have been similar to that in GDM, even in the absence of a definitive diagnosis.

\section{Data collection}

Age at admission, blood pressure, presence of thyroid disease, pre-pregnancy BMI, weight gain during pregnancy and GCT results were collected from the obstetric records. Pregnancy-induced hypertension (PIH), thyroid disease, teenage pregnancy, underweight status $\left(\mathrm{BMI}<18.5 \mathrm{~kg} / \mathrm{m}^{2}\right)$ and poor gestational weight gain $(<5 \mathrm{~kg})$ were used as explanatory variables because they have been previously described as risk factors for SGA. ${ }^{6}{ }^{16-21}$ In the present study, PIH was defined as blood pressure values of $\geq 140 / 90 \mathrm{~mm} \mathrm{Hg}{ }^{22}$ Thyroid disease was defined as hypothyroidism or hyperthyroidism. Pre-pregnancy BMI was calculated according to the WHO standards (bodyweight $(\mathrm{kg}) /$ height $\left.(\mathrm{m})^{2}\right)$. We classified the participants as underweight $\left(<18.5 \mathrm{~kg} / \mathrm{m}^{2}\right)$, normal $\left(18.5-25.0 \mathrm{~kg} / \mathrm{m}^{2}\right)$ and obese $\left(\geq 25.0 \mathrm{~kg} / \mathrm{m}^{2}\right)$ according to the Japan Society of Obstetrics and Gynecology Guidelines for Obstetrical Practice (2014). ${ }^{6}$ Maternal weight gain during pregnancy was calculated by subtracting the participant's pre-pregnancy bodyweight from her bodyweight at the last prenatal visit before delivery. The participants were classified as having poor gestational weight gain $(<5 \mathrm{~kg})$ or non-poor gestational weight gain $(\geq 5 \mathrm{~kg}){ }^{5}$ SGA was defined as infants who had a weight below the 10th centile in each gestational week. ${ }^{23}$

\section{Statistical analyses}

The Mann-Whitney $\mathrm{U}$ test and $\chi^{2}$ test were conducted to compare maternal and neonatal outcomes. Fisher's exact test was used when the expected frequency was $<5$. When we classified women according to their GCT results, a threshold of $90 \mathrm{mg} / \mathrm{dL}$ was chosen because previous studies suggested that women with GCT results of $\leq 90 \mathrm{mg} / \mathrm{dL}$ are at risk for SGA and adverse perinatal outcomes. $^{9} 1524$ Multivariable logistic regression analysis was then carried out by dividing the groups by maternal prepregnancy BMI (underweight, normal and obesity) to examine the association between low GCT results and SGA while controlling for the potential confounding factors. All analyses were performed using Ekuseru-Toukei 2012 (Social Survey Research Information), and the significance level was set at $\mathrm{p}<0.05$.

\section{RESULTS}

The number of births during the study period was 2850 , and 2140 women underwent GCT between 24 and 28 weeks of gestation. Of these births, $1860(65.2 \%)$ were considered eligible for inclusion in this study. The mean maternal age was $31.6 \pm 5.3$ years, with $852(45.8 \%)$ nulliparity, $84(4.5 \%)$ instrumental deliveries and 555 $(33.0 \%)$ caesarean deliveries.

Table 1 lists the clinical characteristics of the enrolled women. The characteristics of the low-GCT and non-low-GCT groups were almost similar, except for the lower maternal age and caesarean delivery rate in the low-GCT group. The overall incidence of SGA was $11.4 \%$ 
Table 1 Clinical characteristics according to maternal glucose challenge test results

\begin{tabular}{|c|c|c|c|}
\hline & \multirow{2}{*}{$\begin{array}{l}\leq 90 \mathrm{mg} / \mathrm{dL} \\
\mathrm{n}=329\end{array}$} & \multicolumn{2}{|c|}{$91-139 \mathrm{mg} / \mathrm{dL}$} \\
\hline & & $\mathrm{n}=1531$ & p Value \\
\hline Maternal age & $30.1 \pm 5.4$ & $31.4 \pm 5.3$ & $<0.01$ \\
\hline Nulliparity & $163(49.5 \%)$ & $689(45.0 \%)$ & 0.14 \\
\hline Caesarean section & $74(22.5 \%)$ & $481(31.4 \%)$ & $<0.01$ \\
\hline Instrumental delivery & $12(3.9 \%)$ & $72(4.7 \%)$ & 0.39 \\
\hline Male sex & $160(48.6 \%)$ & $751(49.0 \%)$ & 0.84 \\
\hline SGA & $51(15.5 \%)$ & $161(10.5 \%)$ & $<0.01$ \\
\hline
\end{tabular}

Values are presented as mean \pm SD or number (\%).

SGA, small for gestational age.

$(212 / 1860)$, and $17.7 \%(329 / 1860)$ of women showed low GCT results. Among the 1860 women, the prevalence of SGA was significantly higher in the low-GCT group than in the non-low-GCT group $(15.5 \%$ vs $10.5 \%$; $\mathrm{p}=0.01$ ) (table 1).

According to categorisation by their BMI, 380 of 1860 $(20.4 \%)$ patients were underweight, $1325 \quad(71.3 \%)$ patients were normal and $155(8.3 \%)$ patients were obese. Low GCT results were significantly associated with SGA ( $p=0.02$; OR 2.10; 95\% CI 1.14 to 3.89$)$ in the underweight group. However, no significant associations were found between low GCT result and SGA in the normal and obesity groups in the multivariable logistic regression analysis (table 2 ).

\section{DISCUSSION}

In this study, low GCT result was significantly associated with SGA births only among pregestational underweight women. A general consensus exists that birth weight is directly related to insulin sensitivity, ${ }^{2} 7$ indicating that maternal carbohydrate metabolism plays an important role in fetal growth. According to these studies, high insulin sensitivity in underweight women during early pregnancy may influence maternal carbohydrate metabolism and maternal periconceptual nutrition. Consequently, lack of insulin resistance may hinder normal carbohydrate metabolism, resulting in low maternal serum glucose levels. Dalfrà et $a t^{2}$ reported that hypoglycaemia may limit fetal glucose supply and eventually result in slow fetal growth as glucose is the main fetal nutrient, which is supplied by the mother. However, this mechanism is difficult to apply in obese women because they are generally less insulin sensitive than the normal-weight population. Low maternal insulin sensitivity before conception is strongly associated with fetal fat accretion. ${ }^{7}$ Thus, low GCT results may have occurred as a result of the high insulin sensitivity that has continued from early pregnancy, particularly in underweight women.

Maternal abdominal palpation and serial measurements of symphysis-fundal height are used as a traditional approach to identify high-risk cases for SGA. However, the detection rate of this approach is $<30 \% .^{25}$ Recently, the combination of fetal parameters, biochemical indices and maternal demographics has been shown to be predictive for SGA. ${ }^{26}$ However, measuring biochemical indices for all pregnant women without additional cost is extremely difficult. Thus, this method is often restricted to high-risk pregnancies. In contrast, if $50 \mathrm{~g}$ GCT may also provide diagnostic information regarding SGA, this method is useful because it is widely used for GDM screening in Japan. Therefore, additional cost or patient examinations are unnecessary.

Our study has several limitations. First, data regarding a prior history of childbirth, intake of alcohol and caffeine, antiphospholipid syndrome, maternal smoking status, kidney disease and inflammatory bowel disease, which may affect insulin sensitivity, were not considered in this study, although these are potential contributors for SGA. ${ }^{62-30}$ Some women with SGA in this study may be affected by the aforementioned risk factors. Second, we hypothesised that low GCT results may have occurred as a result of high insulin sensitivity that has continued from early pregnancy. However, there are no data available regarding the insulin sensitivity of the patients in this study, and we did not investigate the relationship between maternal weight gain and insulin sensitivity. van Raaij et $a l^{31}$ reported that maternal weight gain can influence subsequent maternal insulin resistance; thus, examining their relationship may be necessary. Regular measurement of insulin sensitivity during pregnancy can clarify the relationship between maternal weight gain and GCT results. Third, the generalisability of our findings may be limited by the homogeneity of this cohort, which contained only Japanese women. Finally, although insulin sensitivity might be associated with SGA, using the GCT result as a proxy indicator of insulin sensitivity might be difficult. This is because the former may have low reliability and may be affected by many factors, such as age, body weight, living environment, change in life partner and situation in which the meal was consumed. ${ }^{9}$ According to previous studies, ${ }^{9} 1524$ low GCT results are useful to predict SGA and perinatal adverse outcomes. This study suggests that low GCT results were significantly associated with SGA among pregestational underweight women. In the future, further investigation is necessary to apply low GCT results as a risk factor for SGA. For example, if insulin sensitivity could be 
Table 2 ORs of maternal risk factors for the delivery of a small-for-gestational-age infant analysed separately by maternal weight status

\begin{tabular}{|c|c|c|c|c|c|c|}
\hline \multirow[b]{2}{*}{ Variables } & \multirow[b]{2}{*}{ SGA (n) } & \multirow[b]{2}{*}{ Non-SGA (n) } & \multicolumn{2}{|c|}{ Crude } & \multicolumn{2}{|c|}{ Adjusted } \\
\hline & & & $\overline{\text { OR }}$ & $95 \% \mathrm{Cl}$ & $\overline{\text { OR }}$ & $95 \% \mathrm{Cl}$ \\
\hline \multicolumn{7}{|c|}{$B M I<18.5 \mathrm{~kg} / \mathrm{m}^{2}$} \\
\hline \multicolumn{7}{|c|}{ Low GCT } \\
\hline No & 41 & 256 & 1.0 & Reference & 1.0 & Reference \\
\hline Yes & 20 & 63 & 1.98 & 1.08 to 3.62 & 2.28 & 1.21 to 4.28 \\
\hline \multicolumn{7}{|l|}{$\mathrm{PIH}$} \\
\hline No & 57 & 315 & 1.0 & Reference & 1.0 & Reference \\
\hline Yes & 4 & 4 & 5.52 & 1.34 to 22.7 & 5.58 & 1.29 to 24.1 \\
\hline \multicolumn{7}{|c|}{ Maternal height, $\mathrm{cm}$} \\
\hline$\geq 150$ & 49 & 294 & 1.0 & Reference & 1.0 & Reference \\
\hline$<150$ & 12 & 25 & 2.88 & 1.36 to 6.11 & 3.88 & 1.73 to 8.72 \\
\hline \multicolumn{7}{|c|}{ Thyroid disease } \\
\hline No & 60 & 313 & 1.0 & Reference & 1.0 & Reference \\
\hline Yes & 1 & 6 & 0.87 & 0.10 to 7.35 & 0.79 & 0.09 to 6.89 \\
\hline \multicolumn{7}{|c|}{ Teenage pregnant woman } \\
\hline No & 59 & 306 & 1.0 & Reference & 1.0 & Reference \\
\hline Yes & 2 & 13 & 0.79 & 0.17 to 3.63 & 1.00 & 0.20 to 4.90 \\
\hline \multicolumn{7}{|c|}{ Tertiary perinatal care centre } \\
\hline No & 27 & 179 & 1.0 & Reference & 1.0 & Reference \\
\hline Yes & 34 & 140 & 1.61 & 0.93 to 2.79 & 2.06 & 1.14 to 3.72 \\
\hline \multicolumn{7}{|c|}{$18.5 \leq B M I \leq 25.0 \mathrm{~kg} / \mathrm{m}^{2}$} \\
\hline \multicolumn{7}{|c|}{ Low GCT } \\
\hline No & 105 & 989 & 1.0 & Reference & 1.0 & Reference \\
\hline Yes & 29 & 202 & 1.35 & 0.87 to 2.09 & 1.32 & 0.85 to 2.06 \\
\hline \multicolumn{7}{|l|}{$\mathrm{PIH}$} \\
\hline No & 126 & 1155 & 1.0 & Reference & 1.0 & Reference \\
\hline Yes & 8 & 36 & 2.03 & 0.93 to 4.48 & 1.96 & 0.89 to 4.34 \\
\hline \multicolumn{7}{|c|}{ Maternal height, cm } \\
\hline$\geq 150$ & 121 & 1088 & 1.0 & Reference & 1.0 & Reference \\
\hline$<150$ & 13 & 103 & 1.13 & 0.62 to 2.08 & 1.09 & 0.59 to 2.01 \\
\hline Thyroid dis & & & & & & \\
\hline No & 131 & 1168 & 1.0 & Reference & 1.0 & Reference \\
\hline Yes & 3 & 23 & 1.16 & 0.34 to 3.92 & 1.16 & 0.34 to 3.96 \\
\hline Teenage $p$ & woman & & & & & \\
\hline No & 131 & 1172 & 1.0 & Reference & 1.0 & Reference \\
\hline Yes & 3 & 19 & 1.41 & 0.41 to 4.84 & 1.40 & 0.40 to 4.87 \\
\hline Tertiary pe & sare centre & & & & & \\
\hline No & 69 & 635 & 1.0 & Reference & 1.0 & Reference \\
\hline Yes & 65 & 556 & 1.41 & 0.41 to 4.83 & 1.07 & 0.75 to 1.54 \\
\hline$B M I>25.0$ & & & & & & \\
\hline Low GCT & & & & & & \\
\hline No & 15 & 125 & 1.0 & Reference & 1.0 & Reference \\
\hline Yes & 2 & 13 & 1.28 & 0.26 to 6.23 & 1.58 & 0.25 to 9.96 \\
\hline $\mathrm{PIH}$ & & & & & & \\
\hline No & 13 & 127 & 1.0 & Reference & 1.0 & Reference \\
\hline Yes & 4 & 11 & 3.55 & 0.99 to 12.8 & 4.34 & 1.09 to 17.3 \\
\hline Maternal $\mathrm{h}$ & & & & & & \\
\hline$\geq 150$ & & & 1.0 & Reference & 1.0 & Reference \\
\hline$<150$ & & & & & 6.74 & 1.88 to 24.2 \\
\hline Thyroid dis & & & & & & \\
\hline No & 16 & 135 & 1.0 & Reference & 1.0 & Reference \\
\hline Yes & 1 & 3 & 2.81 & 0.28 to 28.7 & 1.51 & 0.12 to 19.6 \\
\hline Teenage $p$ & woman & & & & & \\
\hline No & 16 & 137 & 1.0 & Reference & 1.0 & Reference \\
\hline Yes & 1 & 1 & 8.5 & 0.51 to 143.6 & 14.3 & 0.73 to 281.7 \\
\hline Tertiary pe & are centre & & & & & \\
\hline No & 11 & 90 & 1.0 & Reference & 1.0 & Reference \\
\hline Yes & 6 & 48 & 1.02 & 0.36 to 2.93 & 1.07 & 0.75 to 1.54 \\
\hline
\end{tabular}


measured on the same day of GCT examination, further evidence may be obtained for the relationship between low GCT results and SGA.

Although some limitations exist, the design and number of participants were the strengths of this study. First, since we collected the data from two hospitals, the generalisability of results may be relatively high. One hospital is a general community hospital, and the other is a tertiary perinatal care centre. Second, conducting the analyses by each prenatal weight status was possible because the number of participants was relatively large. However, with regard to the subanalysis according to maternal weight status, this study is probably underpowered. Therefore, we would like to conduct a more large-scale prospective study in the future.

In conclusion, low $50 \mathrm{~g}$ GCT results were significantly associated with SGA among pregestational underweight women. These results suggest that women who were underweight before pregnancy with low GCT results may be considered as relatively high-risk cases. In addition, the association between insulin sensitivity and fetal growth should be examined in future studies.

\section{Author affiliations}

${ }^{1}$ Department of Obstetrics and Gynecology, Yamanashi Prefectural Central Hospital, Kofu, Japan

${ }^{2}$ Department of Obstetrics and Gynecology, Kofu Municipal Hospital, Kofu, Japan

${ }^{3}$ Faculty of Medicine, Department of Obstetrics and Gynecology, University of Yamanashi, Chuo, Japan

${ }^{4}$ Department of Health and Psychosocial Medicine, Aichi Medical University School of Medicine, Yazakokarimata, Japan

Contributors SS, SH and KS contributed to the conception or design of the work. SS, YU and MH were involved in the data collection. SS and KS carried out data analysis and interpretation. SS, SH and KS participated in the drafting of the article. SS, SH and KS were responsible for the critical revision of the article. SS, YU, SH, MH and KS gave final approval of the version to be published.

Funding This research received no specific grant from any funding agency in the public, commercial or not-for-profit sectors.

Competing interests None declared.

Patient consent Obtained.

Ethics approval The Human Subjects Review Committee of Yamanashi Prefectural Central Hospital and Kofu Municipal Hospital reviewed and approved the study design.

Provenance and peer review Not commissioned; externally peer reviewed.

Data sharing statement No additional data are available.

Open Access This is an Open Access article distributed in accordance with the Creative Commons Attribution Non Commercial (CC BY-NC 4.0) license, which permits others to distribute, remix, adapt, build upon this work noncommercially, and license their derivative works on different terms, provided the original work is properly cited and the use is non-commercial. See: http:// creativecommons.org/licenses/by-nc/4.0/

\section{REFERENCES}

1. Mclntire DD, Bloom SL, Casey BM, et al. Birth weight in relation to morbidity and mortality among newborn infants. $N$ Engl $J$ Med 1999;340:1234-8.

2. Dalfrà MG, Pacini G, Parretti E, et al. Elevated insulin sensitivity and $\beta$-cell function during pregnancy in mothers of growth-restricted newborns. Am J Physiol Endocrinol Metab 2011;301:E25-30.
3. Lindqvist PG, Molin J. Does antenatal identification of small-for-gestational age fetuses significantly improve their outcome? Ultrasound Obstet Gynecol 2005;25:258-64.

4. Familiari $A$, Bhide $A$, Morlando $M$, et al. Mid-pregnancy fetal biometry, uterine artery Doppler indices and maternal demographic characteristics: role in prediction of small-for-gestational-age birth. Acta Obstet Gynecol Scand 2016;95:238-44.

5. Figueras F, Gratacós E. Update on the diagnosis and classification of fetal growth restriction and proposal of a stage-based management protocol. Fetal Diagn Ther 2014;36:86-98.

6. Minakami H, Maeda T, Fujii T, et al. Guidelines for obstetrical practice in Japan: Japan Society of Obstetrics and Gynecology (JSOG) and Japan Association of Obstetricians and Gynecologists (JAOG) 2014 edition. J Obstet Gynaecol Res 2014;40:1469-99.

7. Catalano PM, Kirwan JP, Haugel-de Mouzon S, et al. Gestational diabetes and insulin resistance: role in short- and long-term implications for mother and fetus. J Nutr 2003;133:1674-83.

8. Caruso A, Paradisi G, Ferrazzani S, et al. Effect of maternal carbohydrate metabolism on fetal growth. Obstet Gynecol 1998;92:8-12.

9. Shinohara S, Hirai M, Hirata S, et al. Relation between low 50-g glucose challenge test results and small-for-gestational-age infants. J Obstet Gynaecol Res 2015;41:1752-6.

10. Arnlöv J, Pencina MJ, Nam BH, et al. Relations of insulin sensitivity to longitudinal blood pressure tracking: variations with baseline age, body mass index, and blood pressure. Circulation 2005;112:1719-27.

11. Gonzales MM, Tarumi T, Miles SC, et al. Insulin sensitivity as a mediator of the relationship between BMI and working memory-related brain activation. Obesity (Silver Spring) 2010;18:2131-7.

12. Vadakekut ES, McCoy SJ, Payton ME. Association of maternal hypoglycemia with low birth weight and low placental weight: a retrospective investigation. J Am Osteopath Assoc 2010;111:148-52.

13. Melamed N, Hiersch L, Peled Y, et al. The association between low $50 \mathrm{~g}$ glucose challenge test result and fetal growth restriction. $J$ Matern Fetal Neonatal Med 2013;26:1107-11.

14. Bienstock JL, Holcroft CJ, Althaus J. Small fetal abdominal circumference in the second trimester and subsequent low maternal plasma glucose after a glucose challenge test is associated with the delivery of a small-for-gestational age neonate. Ultrasound Obstet Gynecol 2008;31:517-19.

15. Ma KK, Mele L, Landon MB, et al. The obstetric and neonatal implications of a low value on the $50-\mathrm{g}$ glucose screening test. Am J Perinatol 2013;30:715-22.

16. Harita N, Kariya M, Hayashi T, et al. Gestational bodyweight gain among underweight Japanese women related to small for-gestational-age birth. J Obstet Gynaecol Res 2012;38: 1137-44.

17. Chiavaroli V, Castorani V, Guidone $\mathrm{P}$, et al. Incidence of infants born small- and large-for-gestational-age in an Italian cohort over a 20-year period and associated risk factors. Ital J Pediatr 2016;26:42.

18. León G, Murcia M, Rebagliato M, et al. Maternal thyroid dysfunction during gestation, preterm delivery, and birthweight. The Infancia y Medio Ambiente Cohort, Spain. Paediatr Perinat Epidemiol 2015;29:113-22.

19. Hinkle SN, Albert PS, Mendola P, et al. Differences in risk factors for incident and recurrent small-for-gestational-age birthweight: a hospital-based cohort study. BJOG 2014;121:1080-8.

20. Fraser AM, Brockert JE, Ward RH. Association of young maternal age with adverse reproductive outcomes. $N$ Engl $J$ Med 1995;332:1113-17.

21. Kozuki N, Katz J, Lee AC, et al. Short maternal stature increases risk of small-for-gestational-age and preterm births in low- and middle-income countries: individual participant data meta-analysis and population attributable fraction. J Nutr 2015;145:2542-50.

22. Magee LA, Abalos E, von Dadelszen $P$, et al. How to manage hypertension in pregnancy effectively. Br J Clin Pharmacol 2011;72:394-401

23. Itabashi K, Fujimura M, Kusuda S, et al. Introduction of new neonatal standard anthropometric measurements. Nihon Shonika Gakkai Zasshi 2010;114:1271-93 (in Japanese).

24. Feinberg JH, Magann EF, Morrison JC, et al. Does maternal hypoglycemia during screening glucose assessment identify a pregnancy at-risk for adverse perinatal outcome? J Perinatol 2005:25:509-13.

25. Bais JM, Eskes M, Pel M, et al. Effectiveness of detection of intrauterine growth retardation by abdominal palpation as screening test in a low risk population: an observational study. Eur J Obstet Gynecol Reprod Biol 2004;116:164-9. 
26. Poon LC, Syngelaki A, Akolekar R, et al. Combined screening for preeclampsia and small for gestational age at 11-13 weeks. Fetal Diagn Ther 2013;33:16-27.

27. Fadigas C, Peeva G, Mendez O, et al. Prediction of small-for-gestational-age neonates: screening by placental growth factor and soluble fms-like tyrosine kinase-1 at 35-37 weeks. Ultrasound Obstet Gynecol 2015;46:191-7.

28. Boggs DA, Rosenberg L, Ruiz-Narvaez EA, et al. Coffee, tea, and alcohol intake in relation to risk of type 2 diabetes in African American women. Am J Clin Nutr 2010;92:960-6.
29. Koppe L, Pelletier CC, Alix PM, et al. Insulin resistance in chronic kidney disease: new lessons from experimental models. Nephrol Dial Transplant 2014;29:1666-74.

30. Capristo E, Mingrone G, Addolorato G, et al. Glucose metabolism and insulin sensitivity in inactive inflammatory bowel disease. Aliment Pharmacol Ther 1999;13:209-17.

31. van Raaij JM, Peek ME, Vermaat-Miedema SH, et al. New equations for estimating body fat mass in pregnancy from body density or total body water. Am J Clin Nutr 1988;48: 24-9. 